Research Article

\title{
Experimental Study on Axial Impact Mitigating Stick-Slip Vibration with a PDC Bit
}

\author{
Yong Wang $\mathbb{D}^{1},{ }^{1}$ Hongjian Ni $\mathbb{D}^{1},{ }^{1}$ Yiliu (Paul) Tu, ${ }^{2}$ Ruihe Wang, ${ }^{1}$ Xueying Wang, \\ Heng Zhang, ${ }^{1}$ Jiaxue Lyu, ${ }^{3}$ and Hongqiao $\mathrm{Xie}^{4,5}$ \\ ${ }^{1}$ School of Petroleum Engineering, China University of Petroleum (East China), Qingdao 266580, China \\ ${ }^{2}$ Department of Mechanical and Manufacturing Engineering, University of Calgary, Calgary, AB, T2N 1N4, Canada \\ ${ }^{3}$ West Company, North China Petroleum Engineering Co., Ltd., Sinopec, Luntai, Xinjiang 841600, China \\ ${ }^{4}$ Sinopec Research Institute of Petroleum Engineering, Beijing $100101 \mathrm{~m}$, China \\ ${ }^{5}$ State Key Laboratory of Shale Oil and Gas Enrichment Mechanisms and Effective Development, Beijing 100101m, China \\ Correspondence should be addressed to Hongjian Ni; nihj@upc.edu.cn
}

Received 27 August 2020; Revised 3 December 2020; Accepted 28 December 2020; Published 8 February 2021

Academic Editor: Wenjun Huang

Copyright (C) 2021 Yong Wang et al. This is an open access article distributed under the Creative Commons Attribution License, which permits unrestricted use, distribution, and reproduction in any medium, provided the original work is properly cited.

\begin{abstract}
Stick-slip vibration reduces the drilling rate of penetration, causes early wear of bits, and threatens the safety of downhole tools. Therefore, it is necessary to study suppression methods of stick-slip vibration to achieve efficient and safe drilling. Field tests show that the use of downhole axial impactors is helpful to mitigate stick-slip vibration and improve rock-breaking efficiency. However, there are many deficiencies in the study of how axial impact load affects stick-slip vibration of a PDC bit. In this paper, based on the two-degrees-of-freedom spring-mass-damper model and similarity theory, a laboratory experiment device for suppressing stick-slip vibration of a PDC bit under axial impact load has been developed, and systematic experimental research has been carried out. The results show that the axial impact force can suppress the stick-slip vibration by reducing the amplitude of weight on bit and torque fluctuations and by increasing the main frequency of torque. The amplitude of impact force affects the choice of the optimal back-rake angle. The impact frequency is negatively correlated with the fluctuation amplitude of the rotary speed. When the impact frequency is greater than $100 \mathrm{~Hz}$, the fluctuation amplitude of the rotary speed will not decrease.
\end{abstract}

\section{Introduction}

Drilling investment accounts for the main part of the cost of oil and gas development. Safe and efficient drilling can greatly reduce the cost and improve the economic benefits of oil field. Stick-slip vibration may cause early damage of drilling tools, low rate of penetration (ROP), and high nonproductive time. Particularly, when a PDC bit is used to drill hard strata, stick-slip vibration becomes more intense [1]. The elimination of stick-slip vibration is helpful to improve ROP and reduce underground safety hazards. Therefore, stick-slip vibration and its suppression methods have been an important topic of research in the drilling industry [2].

In the process of rotary drilling, the discontinuous crushing of the rock is one of the main reasons leading to the stick-slip vibration in the downhole. Therefore, the key to reduce the stick-slip vibration of the drillstring is to suppress the vibration in the rock-breaking process of the bit $[3,4]$. To better understand and ultimately eliminate stick-slip vibration, many drilling service providers have developed downhole vibration measurement instruments, evaluation systems, and vibration-reduction drilling tools. The drilling assembly design, constant torque tool, reactive-torque-free bit, and axial impact drilling technology have been proposed, which can make the bit move with more stability and continuously cut rocks, thus reducing the bit's viscosity and slip-off phenomenon $[5,6]$.

These techniques are effective in reducing the stick-slip vibration of the bit and have been proved by a considerable number of field tests. In particular, axial impactors have an obvious effect in restraining the stick-slip vibration of PDC 
bits, which fully verifies that the impact load plays a key role in restraining stick-slip and other harmful vibrations of the bit [7].

In the research of stick-slip vibration, some researchers simplified the bit, drill collar, and drill pipe into a torsional pendulum model, assuming the boundary at the bit as a velocity-dependent friction boundary, and applied extra force to reduce stick-slip vibration $[8,9]$. However, other researchers think that cutting tooth rock-breaking behavior is the reason for stick-slip. Therefore, through the establishment of a single cutter/rock contact model, stick-slip and its mitigation methods can be studied. As shown in the literature [10], the numerical simulation method reveals that the torsional impact force can reduce the time of cutting and rock breaking, thus reducing the possibility of stick slip.

Some researchers have tried to study the law of stick-slip vibration through laboratory experiments. But some of the devices they built did not take into account the axial flexibility [11-13], and some did not truly reproduce the process of PDC bit drilling [14-19]. To better understand the mechanism and features of mitigating stick slip by axial impact, this article uses similarity theory and a two-degreesof-freedom mass-spring-damper model to develop a laboratory experiment apparatus and investigate stick-slip mitigation by axial impact and how parameters such as bit back-rake angle affect the effects of vibration suppression.

\section{Experimental Model Design}

2.1. Mathematical Model of the Drillstring System. In the process of rock breaking by a PDC bit, a PDC cutter has both axial and torsional motions. The coupling of torsional and axial motions occurs at the cutting teeth. Therefore, the simulation device of a rotary drilling system should consider both axial and torsional dynamics. In this paper, a twodegrees-of-freedom (DOF) mass-spring-damper model and similarity theory are used to design the experimental parameters [20-23].

The simplified model of the drill string system is shown in Figure 1. Torsional stiffness of the drill pipe is simplified as a torsion spring $K_{T}$, and axial stiffness of the drill pipe is simplified as a compression/tension spring $K_{a}$. The rotational damping of drilling fluid is simplified to a linear damping $C_{T}$, while the axial damping of drilling fluid is ignored. The bottom hole assembly (BHA) is simplified to a stiff rotary table with an inertia of $I_{b}$ and a mass of $M_{b}$. The top drive rotary speed, rotary displacement, torque, and axial displacement are represented by $\Omega_{0}, \Phi_{0}, T_{0}$, and $U_{0}$, respectively. The rotary speed, rotary displacement, torque, and axial displacement of the bit and BHA are denoted by $\Omega$, $\Phi, T$, and $U$, respectively. WOB and torque are the axial component $W$ and torsional component $T_{b}$ of the bit cutting force, respectively.
The system axial dynamics is as follows:

$$
M_{b} \ddot{U}+K_{a} U-K_{a} V_{0} t=W_{b}
$$

and the torsional dynamics is expressed as

$$
I_{b} \ddot{\Phi}+C_{T} \dot{\Phi}+K_{T} \Phi-K_{T} \Omega_{0} t=T_{b}
$$

The interaction between the bit and the formation consists of cutting forces and friction forces, which produce reactive force of $W_{b}$ and reactive torque $T_{b}$ in the axial and torsional directions, respectively. Therefore, we have

$$
\begin{gathered}
T_{b}=T_{c}+T_{f}, \\
W_{b}=W_{c}+W_{f},
\end{gathered}
$$

where $T_{c}$ and $T_{f}$ represent the cutting and frictional components of torque and $W_{c}$ and $W_{f}$ refer to the cutting and frictional components of WOB.

2.2. Determination of the Model Scale Parameters. In this section, dimensional analysis is used to derive the model scale parameters. Equations (1) and (2) adopt the MLT dimension system, and their dimension matrixes are presented in Tables 1 and 2, respectively. It is seen from Table 1 that the rank of the dimension matrix of the axial dynamics is 3 , which indicates that there are three independent variables among six physical quantities in equation (1). Therefore, $3(6-3=3)$ similarity criteria exist.

As for Table 2, the rank of the dimension matrix of equation (2) is two, which means only two variables are independent among seven physical quantities. Moreover, given the dimensionless parameter $\Phi, 4 \quad(7-2-1=4)$ similarity criteria are required. Since the mathematic models have already been presented, the integral analogy approach can be used for derivation of the similarity criteria.

According to integral analogy approach, equations (4) and (5) can be obtained by using the 2 nd term in equation (1) and 3 rd term in equation (2) to divide the other terms in respective equations:

$$
\begin{gathered}
\frac{M_{b} \ddot{U}}{K_{a} U}+1-\frac{V_{0} t}{U}-\frac{W}{K_{a} U}=0, \\
\frac{I_{b} \ddot{\Phi}}{K_{T} \Phi}+\frac{C_{T} \dot{\Phi}}{K_{T} \Phi}+1-\frac{\Omega_{0} t}{\Phi}-\frac{T_{b}}{K_{T} \Phi}=0 .
\end{gathered}
$$

The ratios of physical quantities are then used to replace the corresponding derivatives, and seven invariants are obtained: 


$$
\begin{aligned}
& \Pi_{1}=\frac{M_{b}}{K_{a} t^{2}}, \\
& \Pi_{2}=\frac{V_{0} t}{U}, \\
& \Pi_{3}=\frac{W}{K_{a} U}, \\
& \Pi_{4}=\frac{I_{b}}{K_{T} t^{2}}, \\
& \Pi_{5}=\frac{C_{T}}{K_{T} t}, \\
& \Pi_{6}=\frac{\Omega_{0} t}{\Phi}, \\
& \Pi_{7}=\frac{T_{b}}{K_{T} \Phi} .
\end{aligned}
$$

Defining that $C_{M b}, C_{U}, C_{K a}, C_{V 0}, C_{I b}, C_{C T}, C_{\Phi}, C_{K T}, C_{\Omega 0}$, $C_{T}$, and $C_{t}$ represent ratios of corresponding physical quantities, we can conclude that the criterion for similarity between the model and actual case should be $C_{M b}=C_{K a} C_{t}^{2}$, $C_{U}=C_{V 0} C_{t}, \quad C_{w}=C_{K a} C_{U}, \quad C_{I b}=C_{K t} C_{t}^{2}, \quad C_{C T}=C_{K T} C_{t}$, $C_{\Phi}=C_{\Omega 0} C_{t}$, and $C_{T b}=C_{K T} C_{\Phi}$. Furthermore, assuming $C_{t}=1$ and $C_{\Phi}=1$, we can simplify the similarity criteria into $C_{M b}=C_{K a}, \quad C_{U}=C_{V 0}, \quad C_{W}=C_{K a} C_{U}, \quad C_{I b}=C_{C T}=C_{K T}=C_{T b}$, and $C_{\Omega 0}=1 . C_{T b} / C_{W}=C_{a}$ is the geometry ratio of the model, namely, the ratio of the drilling footage of the model to the actual drilling footage $C_{U}$, and $\mathrm{Ca}$ stands for the ratio of the diameter of the model bit to that of the actual bit.

Table 3 demonstrates that the drill bit diameter $a=0.108 \mathrm{~m}$, and the drill bit radius defined in this paper equals $0.028 \mathrm{~m}$. Thus, $C_{U}=C_{a}=0.028 / 0.108=0.26$. In this paper, $M_{b}=2000 \mathrm{~kg}$ and $C_{K a}=C_{M b}=2000 / 11000=0.18$; therefore, $C_{\mathrm{W}}=C_{K a} C_{U}=0.0468$ and $C_{I b}=C_{C T}=C_{K T}=C_{T b}=$ $C_{W} C_{a}=0.012$. Model scale parameters are shown in Table 3.

2.3. Experimental Apparatus. The schematic diagram of the laboratory model is illustrated in Figure 2. The driving motor drives the torsion bar spring to rotate, and the torsion bar passes torque to the rotary inertia plate through the torque drive mechanism and finally to the drill bit. The torsional spring simulates the torsional elasticity of the drillstring, the rotary plate simulates the rotational inertia of the BHA, and the mass block simulates the mass of the drill string. The drillstring drives the motor to simulate the rotary table, and the speed can be adjusted through the frequency converter. The speed adjustment range is $0 \sim 500$ revolutions per minute (RPM). The servo motor drives the rotor of the impactor to rotate and produces impact force, which can be adjusted through the frequency converter, and the impact force is transmitted to the bit through the drive shaft. The servo motor drives the lift up and down to simulate the rise and fall of the hook, and the spring simulates the axial elasticity of the drill string. The lower part of the lift is connected with the concentrated mass block through the

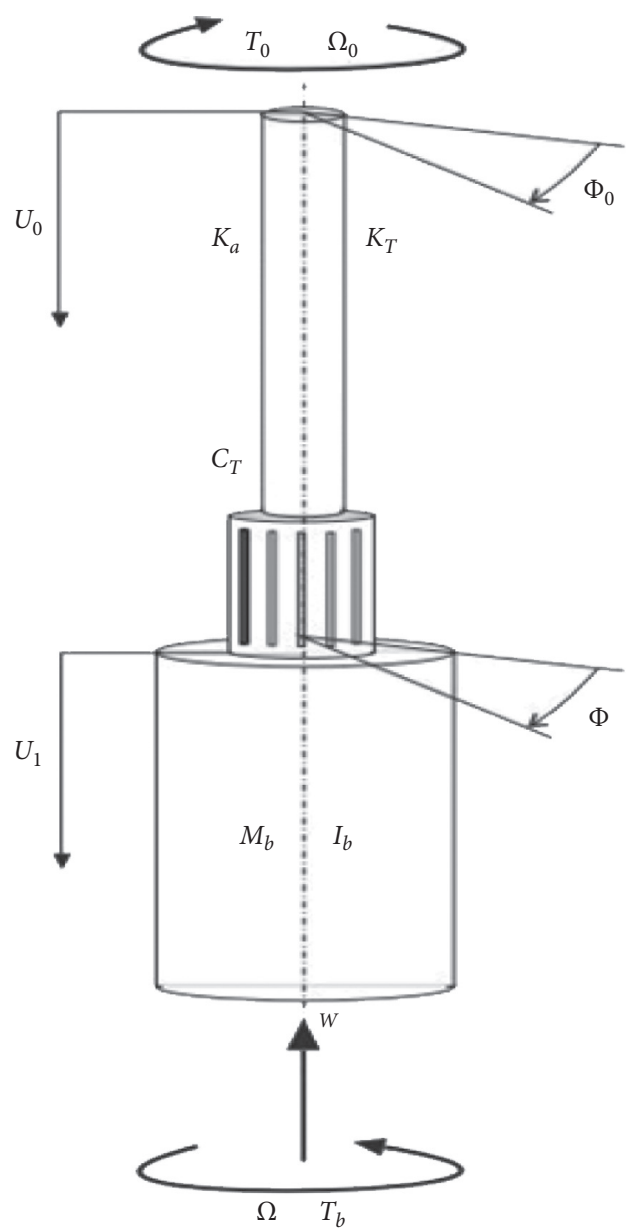

FIgURE 1: Schematic diagram of the 2 DOFs model of the drilling string.

TABLE 1: Dimensions of the axial dynamics of the drillstring system.

\begin{tabular}{lcccccc}
\hline \multicolumn{2}{l}{ Physical quantity } & & & & & \\
Dimension & $M_{\mathrm{b}}$ & $K_{a}$ & $V_{0}$ & $t$ & $U$ & $W$ \\
\hline $\mathrm{M}$ & 1 & 1 & 0 & 0 & 0 & 1 \\
$\mathrm{~L}$ & 0 & 0 & 1 & 0 & 1 & 1 \\
$\mathrm{~T}$ & 0 & -2 & -1 & 1 & 0 & -2 \\
\hline
\end{tabular}

Table 2: Dimensions of the torsional dynamics of the drillstring system.

\begin{tabular}{lccccccc}
\hline \multicolumn{2}{l}{ Physical quantity } & & & & & & \\
Dimension & $I_{b}$ & $C_{T}$ & $K_{T}$ & $\Omega_{0}$ & $t$ & $T$ & $\Phi$ \\
\hline $\mathrm{M}$ & 1 & 1 & 1 & 0 & 0 & 1 & 0 \\
$\mathrm{~L}$ & 2 & 2 & 2 & 0 & 0 & 2 & 0 \\
$\mathrm{~T}$ & 0 & -1 & -2 & -1 & 1 & -2 & 0 \\
\hline
\end{tabular}

disc spring, beam, and column, and the concentrated mass block simulates the mass of the drill string. The permanent magnet DC motor is connected to the end of the torsional spring to simulate the drill string rotation damping. The torsion natural frequency is $\omega_{t}=0.97 \mathrm{~Hz}$, and the axial natural frequency is $\omega_{v}=6.5 \mathrm{~Hz}$. 
TABLE 3: Model scale parameters for the experimental model.

\begin{tabular}{|c|c|c|c|c|}
\hline Name & Parameter & Actual value & Model value & Unit \\
\hline Axial rigidity & $K_{a}$ & $7.0^{*} 10^{5}$ & $4.13^{*} 0^{4}$ & $\mathrm{~N} / \mathrm{m}$ \\
\hline Torsional rigidity & $K_{T}$ & 940 & 3.7 & $\mathrm{Nm} / \mathrm{rad}$ \\
\hline Mass & $M_{a}$ & $1.1^{*} 10^{4}$ & $2^{*} 10^{3}$ & $\mathrm{Kg}$ \\
\hline Rotational inertia & $I_{b}$ & 115.3 & 1.38 & $\mathrm{Kg} \mathrm{m}^{2}$ \\
\hline Bit radius & $a$ & 0.108 & 0.028 & $\mathrm{~m}$ \\
\hline Rotational damping coefficient & $C_{T}$ & 0.1 & 0.0012 & - \\
\hline
\end{tabular}

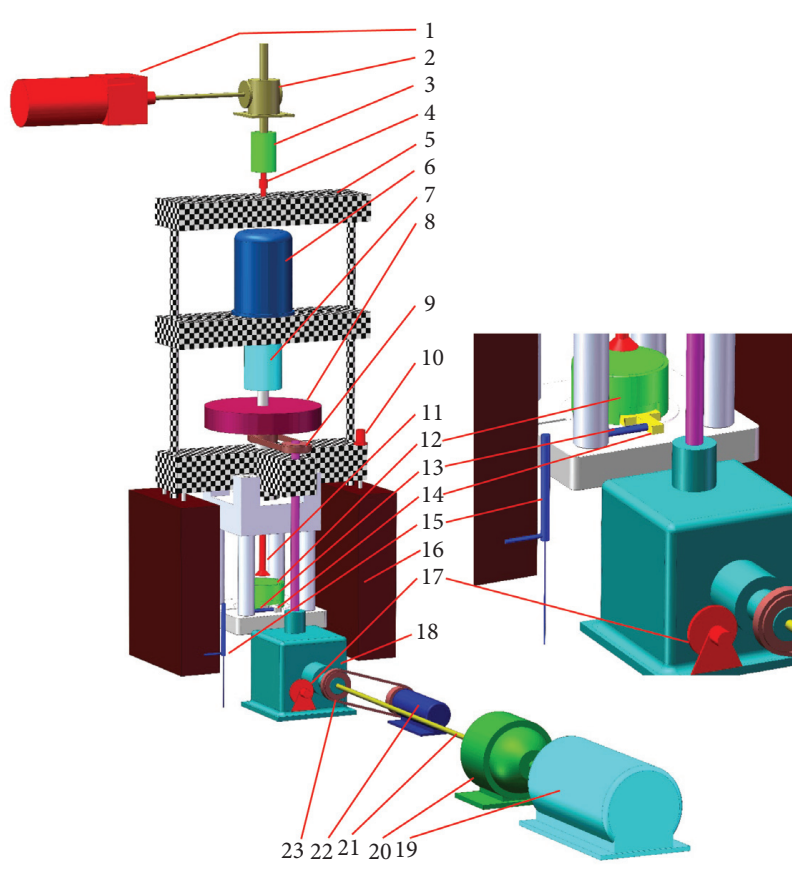

FIGURE 2: Experimental apparatus for stick slip mitigation by axial impact. 1 Servo motor; 2 Lifter; 3 Disc spring; 4 Tension sensor; 5 Lifting framework (parts marked with black-and-white grids as a whole are referred to as the lifting framework); 6 Impactor motor; 7 Impactor; 8 Spindle; 9 Rotational inertia wheel; 10 Chain mechanism; 11 Base (the grey white mechanism as a whole is referred to as the base); 12 Link mechanism; 13 Bit; 14 Core sample holder; 15 Pendulum rod; 16 Torque sensor; 17 Balancing weight; 18 Commutator; 19 Angular velocity sensor; 20 Drill string drive motor; 21 Reducer; 22 Torsion rod spring; 23 Permanent magnetic DC motor; 24 Chain mechanism.

\section{Experimental Results and Discussion}

3.1. Analysis of Torsional Vibration Mechanism. In this section, the drilling experiment under ordinary condition (no axial impact) is carried out to demonstrate that the apparatus can reproduce stick-slip vibration and study features of stick-slip vibration. The rotation speed, WOB, and torque measured while drilling are shown in Figure 3. The average values of $\mathrm{WOB}$ and torque are $4.7 \mathrm{kN}$ and $130 \mathrm{~N}$ $\mathrm{m}$, respectively, and the ratio of torque to $\mathrm{WOB}$ is $27.7 \mathrm{~N} \mathrm{~m} /$ $\mathrm{kN}$. For the convenience of description, the time is divided into three stages according to the amplitude of rotation speed fluctuation: stable period $(0-5 \mathrm{~S})$, transitional period (6-13s), and stick-slip period (14-19s). The amplitude of rotation speed fluctuation in the three stages is $24 \mathrm{RPM}$, $62 \mathrm{RPM}$, and $120 \mathrm{RPM}$, respectively. The amplitude of WOB fluctuation is $0.78 \mathrm{kN}, 0.86 \mathrm{kN}$, and $0.99 \mathrm{kN}$, respectively, and the amplitude of torque fluctuation is $93 \mathrm{~N} \mathrm{~m}, 96 \mathrm{~N} \mathrm{~m}$, and $124 \mathrm{~N} \mathrm{~m}$, respectively.

The spectrum analysis of rotation speed, WOB, and torque is shown in Figure 4. Stable period: main frequency of rotation speed is $0.48 \mathrm{~Hz}$ and second-order frequency is $0.97 \mathrm{~Hz}$; the main frequency of WOB is close to the amplitude of the second-order and third-order frequency. The main frequency and second-order frequency of torque are $0.488 \mathrm{~Hz}$ and $0.244 \mathrm{~Hz}$, and there is no significant peak near the natural frequency $\omega_{t}$ of torque. Transitional period: the main frequencies of rotation speed, bit pressure, and torque are all $\omega_{t}$, and the amplitude of the second-order frequency $(0.488 \mathrm{~Hz})$ in the WOB spectrum is close to that of the main frequency. Stick-slip period: the main frequency of each spectrum is $\omega_{t}$, and the amplitude of the frequency is significantly different from that of the second-order frequency. The main frequency of torque is close to the natural frequency $\omega_{t}$ of the system, which resonates and ultimately leads to stick-slip vibration.

The spectrum analysis shows that the main frequency of stick-slip vibration is the first-order torsional natural frequency of BHA and is not related to bit-rock interaction, which is consistent with the conclusions obtained from field measurements. Bit-rock interactions produce torques of different frequencies, but only first-order resonance can be excited. 

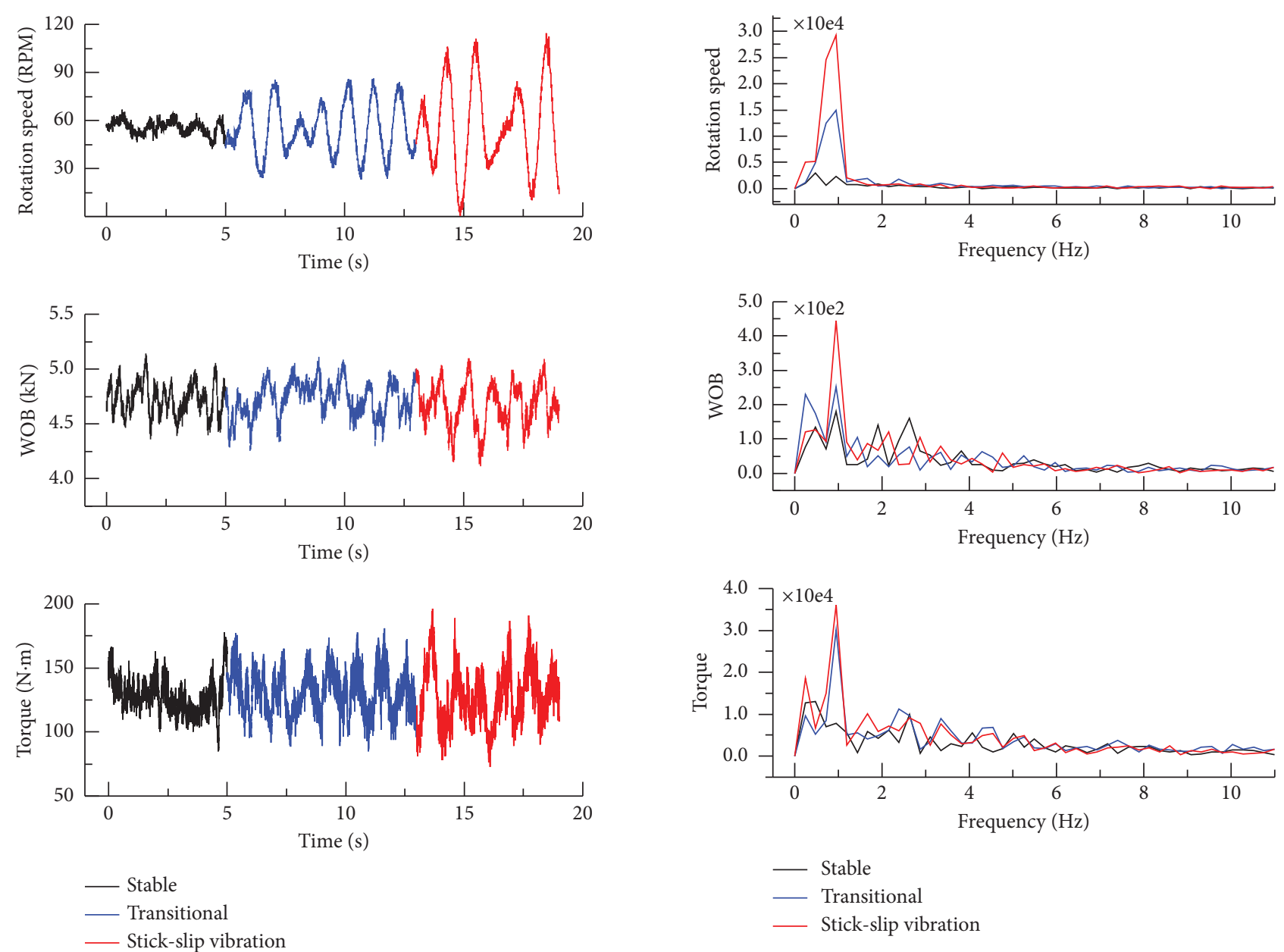

Figure 3: Process of stick-slip vibration generation and development.

3.2. Mechanism of Axial Impact Mitigating Stick Slip. In this section, an experimental study on the suppression of torsional vibration by axial impact is carried out, and the results are shown in Figure 5. In this experiment, the amplitude of impact force was $5 \mathrm{kN}$ and the frequency was $200 \mathrm{~Hz}$. Under the impact condition, the average $\mathrm{WOB}$ is $4.28 \mathrm{kN}$ and the average torque is $85 \mathrm{~N} \mathrm{~m}$. The rotation speed, torque, and WOB fluctuation amplitude are $36 \mathrm{RPM}, 70 \mathrm{~N} \mathrm{~m}$, and $7.9 \mathrm{kN}$, respectively.

Compared with Figure 3, the fluctuation rate of WOB under the axial impact increased by $597 \%$, but the average WOB and average torque decreased by $8.9 \%$ and $35 \%$, respectively, and the fluctuation amplitude of rotation speed and torque decreased by $70 \%$ and $44 \%$, respectively.

Spectrum analysis of rotation speed, $\mathrm{WOB}$, and torque is shown in Figure 6. The main frequencies of rotation speed, $\mathrm{WOB}$, and torque are $0.97 \mathrm{~Hz}, 200 \mathrm{~Hz}$, and $2.44 \mathrm{~Hz}$, respectively. The main frequency of torque is far greater than the natural frequency of the system $\omega_{t}$, and resonance cannot occur, so the rotation speed is relatively stable.

3.3. Effects of Back-Rake Angle and Impact Frequency. The back-rake angle of PDC teeth has an important effect on the torsional stability of drillstring. The influence of impact

Figure 4: Frequency spectrum of rotation speed, WOB, and torque.

load amplitude and PDC back-rake angle on rotation speed is shown in Figure 7. The back-rake angle of PDC teeth determines the cutting force characteristics of the drill bit and also affects the torsional stability of the drillstring. With the impact amplitude unchanged, the drillstring fluctuation first weakens and then increases as the backrake angle increases, and there is an optimal back-rake angle with the weakest fluctuation. When impact force is zero, the PDC back-rake angle with the minimum rotation speed fluctuation amplitude is $17^{\circ}$. When the amplitude of impact force increases from $1000 \mathrm{~N}$ to $5000 \mathrm{~N}$, the optimal back-rake angle gradually decreases to $12^{\circ}$. When the backrake angle is greater than $5^{\circ}$, the fluctuation of rotation speed decreases as impact force increases. With the increase of the back-rake angle, the impact amplitude decreases. When the back-rake angle is greater than $15^{\circ}$, the impact force will even cause the rotation speed to fluctuate more severely.

The influence of impact frequency on rotation speed is shown in Figure 8, when the back-rake angle and impact amplitude remain unchanged. The back-rake angle of the $\mathrm{PDC}$ bit is $10^{\circ}$, and the impact amplitude is $5 \mathrm{KN}$. When the impact frequency is lower than $100 \mathrm{~Hz}$, the fluctuation of rotational speed decreases linearly with the increase of the 

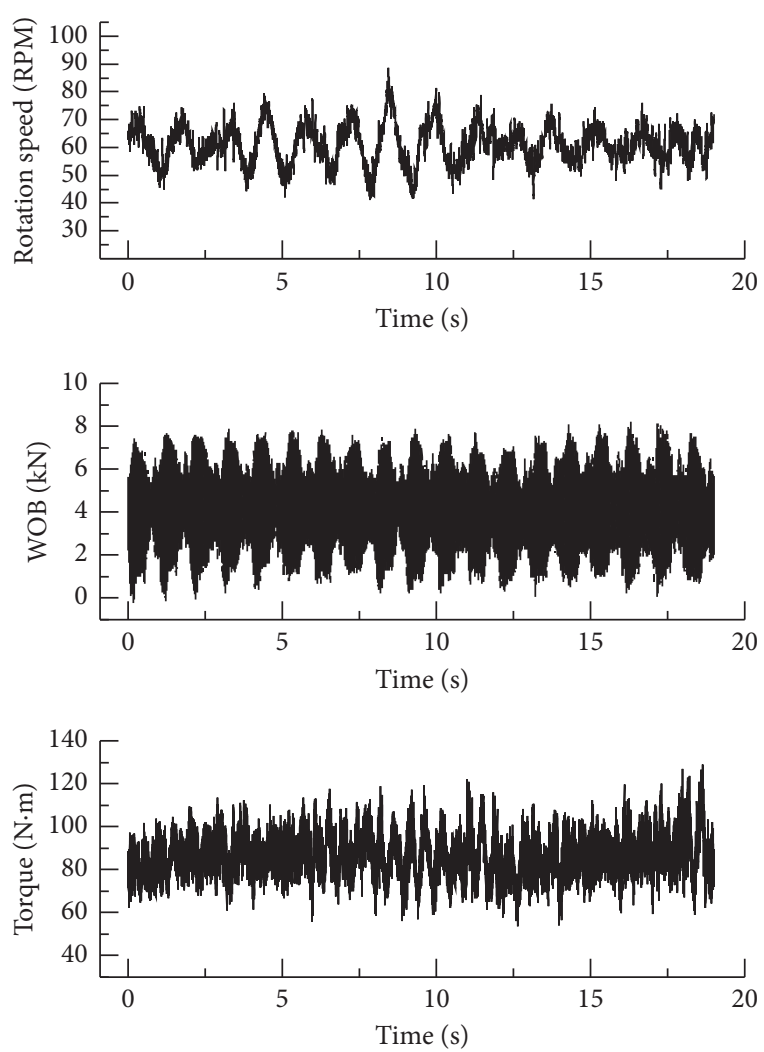

FIGURE 5: Test result of suppressing stick slip by axial impact.
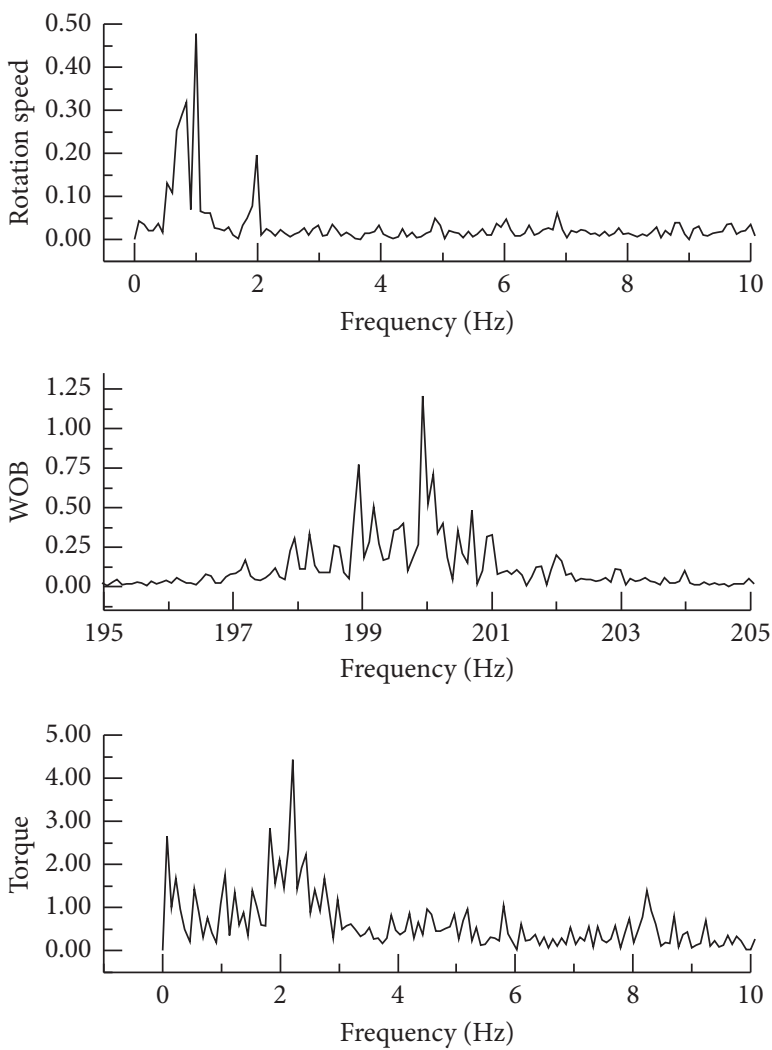

FIGURE 6: Frequency spectrum of WOB, rotation speed, and torque under axial impact.

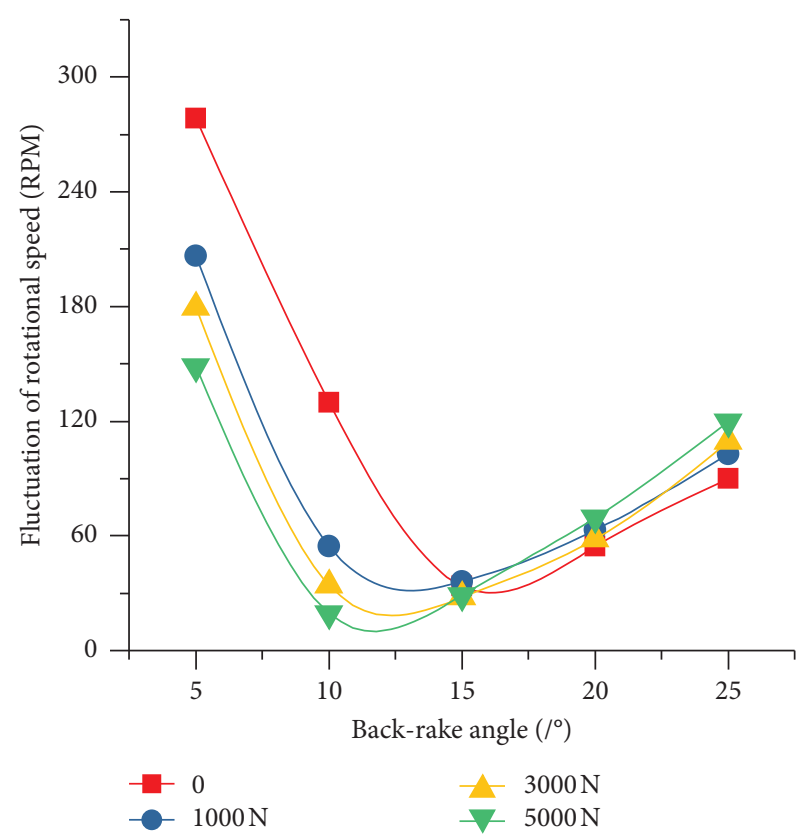

FIgURE 7: Experimental results of torsional stability of drillstring.

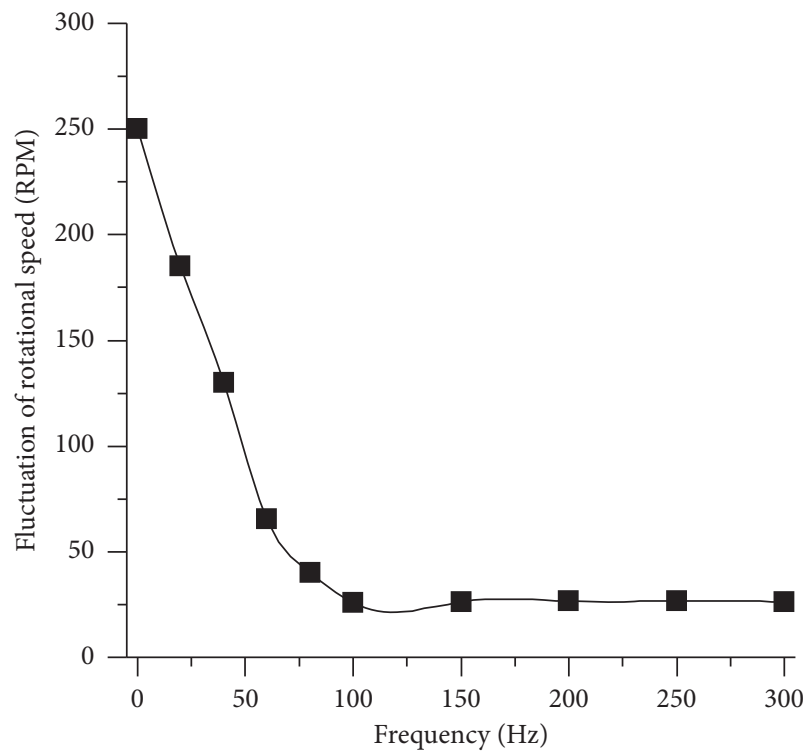

FIGURE 8: Influence of impact frequency on torsional stability of drillstring.

impact frequency. When the impact frequency is greater than $100 \mathrm{~Hz}$, the rotation speed fluctuation is constant at 24 RPM.

\section{Conclusions}

Based on the 2 DOFs drillstring dynamics and similarity theory, this paper designed and built an experimental apparatus to study stick-slip mitigation by axial impact. The main findings of this paper are as follows:

(1) In conventional drilling, the main frequency of torque is consistent with the torsion natural frequency of the 
system in the period of stability and transition, resonance is generated accordingly, and the fluctuation of rotation speed increases gradually.

(2) Under the impact condition, the average WOB, average torque, and torque fluctuation decreased significantly.

(3) The impact force makes the main frequency of torque far higher than the first-order natural frequency of drillstring, thus eliminating resonance and inhibiting stick slip.

(4) When the amplitude and frequency of impact force are constant, there is a back-rake angle with the weakest fluctuation.

(5) When the impact frequency is lower than $60 \mathrm{~Hz}$, the higher the impact frequency is, the weaker the rotation speed fluctuation will be. When the impact frequency exceeds $100 \mathrm{~Hz}$, the fluctuation amplitude of rotation speed remains constant.

\section{Data Availability}

The raw data (experiment measurement) are available upon request to the corresponding author.

\section{Conflicts of Interest}

The authors declare that they have no conflicts of interest.

\section{Authors' Contributions}

Yong Wang designed the experiment and wrote the paper. Jiaxue Lyu and Hongqiao Xie made some suggestions for the design of the experimental device. Hongjian Ni, Paul Tu, and Ruihe Wang provided useful advice for the paper. Xueying Wang and Heng Zhang carried out these experiments.

\section{Acknowledgments}

This work was sponsored by the National Natural Science Foundation of China (Grant no. 51704323) and Science and Technology Major Project of the China National Petroleum Corporation (Grant no. ZD2019-183-005).

\section{References}

[1] M. T. Albdiry and M. F. Almensory, "Failure analysis of drillstring in petroleum industry: a review," Engineering Failure Analysis, vol. 65, pp. 74-85, 2016.

[2] A. Ghasemloonia, D. Geoff Rideout, and S. D. Butt, "A review of drillstring vibration modeling and suppression methods," Journal of Petroleum Science and Engineering, vol. 131, pp. 150-164, 2015.

[3] T. Richard, C. Germay, and E. Detournay, "A simplified model to explore the root cause of stick-slip vibrations in drilling systems with drag bits," Journal of Sound and Vibration, vol. 305, no. 3, pp. 432-456, 2007.

[4] J. M. Kamel and A. S. Yigit, "Modeling and analysis of stickslip and bit bounce in oil well drillstrings equipped with drag bits," Journal of Sound and Vibration, vol. 333, no. 25, pp. 6885-6899, 2014.
[5] S. Liu, H. Ni, X. Wang, Y. Wang, and P. Wang, "Rockbreaking mechanism study of axial and torsional impact hammer and its application in deep wells," in Proceedings of IADC/SPE Asia Pacific Drilling Technology Conference and Exhibition, August 2018.

[6] T. Feng, S. Bakshi, Q. Gu, Z. Yan, and D. Chen, "Design optimization of bottom-hole assembly to reduce drilling vibration," Journal of Petroleum Science and Engineering, vol. 179, pp. 921-929, 2019.

[7] G. Dong and P. Chen, "A review of the evaluation, control, and application technologies for drill string vibrations and shocks in oil and gas well," Shock and Vibration, vol. 2016, Article ID 7418635, 34 pages, 2016.

[8] J. Tian, C. Fan, T. Zhang, and Y. Zhou, "Rock breaking mechanism in percussive drilling with the effect of highfrequency torsional vibration," Energ Source Part A, 2019.

[9] E. M. Navarro-López and D. Cortés, "Avoiding harmful oscillations in a drillstring through dynamical analysis," Journal of Sound and Vibration, vol. 307, no. 1-2, pp. 152-171, 2007.

[10] S. Liu, H. Ni, X. Wang, P. Wang, and N. Li, "Numerical study of the compound vertical and horizontal impact cutting with a single PDC cutter," Energy Reports, vol. 6, pp. 1520-1527, 2020.

[11] H. Melakhessou, A. Berlioz, and G. Ferraris, "A nonlinear well-drillstring interaction model," Journal of Vibration and Acoustics, vol. 125, no. 1, pp. 46-52, 2003.

[12] N. Mihajlovic, N. Van De Wouw, M. P. M. Hendriks, and H. Nijmeijer, "Friction-induced limit cycling in flexible rotor systems: an experimental drill-string set-up," Nonlinear Dynamics, vol. 46, no. 3, pp. 273-291, 2006.

[13] D. W. Raymond, M. A. Elsayed, Y. Polsky et al., "Laboratory simulation of drill bit dynamics using a model-based servohydraulic controller," Journal of Energy Resources Technology, vol. 130, no. 4, Article ID 043103, 2008.

[14] Y. A. Khulief and F. A. Al-sulaiman, "Laboratory investigation of drillstring vibrations," Proceedings of the Institution of Mechanical Engineers, Part C: Journal of Mechanical Engineering Science, vol. 223, no. 10, pp. 2249-2262, 2009.

[15] C. Canudas-de-Wit, F. R. Rubio, and M. A. Corchero, "DOSKIL: a new mechanism for controlling stick-slip oscillations in oil well drillstrings," IEEE Transactions on Control Systems Technology, vol. 16, no. 6, pp. 1177-1191, 2008.

[16] H. C. Lu, J. Dumon, and C. Canudasdewit, "Experimental study of the D-OSKIL mechanism for controlling the stickslip oscillations in a drilling laboratory testbed," in Proceedings of the international conference on control applications, Russia, July 2009.

[17] I. Forster, A. H. W. Macfarlane, and R. Dinnie, "Asymmetric vibration damping tool-small scale rig testing and full scale field testing," in Proceedings of IADC/SPE Drilling Conference and Exhibition, New Orleans, LA, USA, February 2010.

[18] I. Forster, "Axial excitation as a means of stick slip mitigationsmall scale rig testing and full scale field testing," in Proceedings of IADC/SPE Drilling Conference and Exhibition, Amsterdam, Netherlands, March 2011.

[19] P. A. Patil and C. Teodoriu, "A comparative review of modelling and controlling torsional vibrations and experimentation using laboratory setups," Journal of Petroleum Science and Engineering, vol. 112, no. 1, pp. 227-238, 2013.

[20] M. Wiercigroch, K. Nandakumar, L. PEI, M. Kapitaniak, and V. Vaziri, "State dependent delayed drill-string vibration: theory, experiments and new model," Procedia IUTAM, vol. 22, no. 1, pp. 39-50, 2017. 
[21] X. Zheng and B. Balachandran, "State-dependent delay and drill-string dynamics," Procedia IUTAM, vol. 22, no. 1, pp. 31-38, 2017.

[22] K. Nandakumar and M. Wiercigroch, "Stability analysis of a state dependent delayed, coupled two DOF model of drillstringvibration," Journal of Sound and Vibration, vol. 332, no. 10 , pp. $2575-2592,2013$.

[23] Q. Xue, H. Leung, L. Huang et al., "Modeling of torsional oscillation of drillstring dynamics," Nonlinear Dynamics, vol. 96, no. 1, pp. 267-283, 2019. 